\title{
Do rebel workers in the honeybee Apis mellifera avoid worker policing?
}

\author{
Wiktoria RoJeK, Karolina KuszewsKa, Monika OstaP-Chęć, Michał WoyciechowsKi \\ Institute of Environmental Sciences, Jagiellonian University, Gronostajowa 7, 30-387, Krakow, Poland
}

Received 8 November 2018 - Revised 5 July 2019 - Accepted 10 September 2019

\begin{abstract}
A recent study showed that worker larvae fed in a queenless colony develop into another female polyphenic form - rebel workers. The rebel workers are more queen-like than normal workers because they have higher reproductive potential revealed by more ovarioles in their ovaries. However, it was unclear whether eggs laid by rebel workers avoided worker policing. Worker-laid eggs are normally eaten by other workers in a queenright colony. The aim of this study was to compare the survival of three classes of eggs, namely, those laid by normal workers, rebel workers, and the queen. All eggs were tested in queenright colonies. We expected that rebel workers would avoid policing by laying more queen-like eggs. Contrary to our expectations, eggs laid by rebel workers were eaten by other workers, as were eggs laid by normal workers, and only a few worker-laid eggs (both normal and rebel) survived for more than $3 \mathrm{~h}$. Therefore, in a queenright colony, eggs laid by rebel workers do not avoid policing.
\end{abstract}

\section{Worker policing / Rebel workers / Laying workers / Apis mellifera}

\section{INTRODUCTION}

Honeybee societies are characterized by the reproductive division of labour, in which the queen is typically the only reproductive member of the colony while workers are facultatively sterile and refrain from reproducing in the presence of the queen (Wilson 1971; Bourke 1988). The existence of such altruistic behaviour of workers was explained by Hamilton (1964a, b) through inclusive fitness theory. This theory predicts that workers have higher inclusive fitness if they forego their own reproduction and rear the offspring of their polyandrous mother (queen), thereby increasing her reproductive success. Although honeybee workers are facultatively sterile, they retain the potential to lay unfertilized eggs, from which males develop (Dzierzon 1845, cited in Buttel-

Corresponding author: W. Rojek, wiktoria.rojek@doctoral.uj.edu.pl Handling editor: David Tarpy
Reepen 1915). Male production by workers is subject to a great potential conflict in honeybee societies because workers are on average more closely related to the queen's sons (brothers, $r=$ 0.25 ) than to other workers' sons (full- and halfnephews, $r<0.25$ ). Therefore, workers could benefit from curtailing other workers' reproduction and police one another against laying maledetermined eggs (Woyciechowski and Lomnicki 1987; Ratnieks and Vischer 1989). Despite recent controversy (Foster et al. 2006), inclusive fitness theory is very successful in explaining worker policing (Wenseleers and Ratnieks 2006). However, factors other than relatedness, such as sensitivity to dehydration, might also play a role in the removal of worker-laid eggs (Wegener et al. 2010). Worker policing describes any behaviour of workers that inhibits the reproduction of other workers (Ratnieks 1988). This behaviour involves aggression towards reproductively active workers (Ratnieks and Visscher 1989; van der Blom 1991; Visscher and Dukas 1995; Dampney et al. 2002) and, more commonly, the selective removal of 
worker-laid eggs via oophagy (Ratnieks and Visscher 1989; Ratnieks 1993, 1995). Worker policing effectively reduces the rearing of workers' sons. In queenright colonies, $7 \%$ of the male eggs are laid by workers, but only $0.1 \%$ of the adult males are workers' sons (Visscher 1989, 1996). The proportion of workers with mature ovaries in normal queenright colonies is extremely low, as only $0.01 \%$ of workers have eggs in their ovaries, which indicates that they lay eggs (Ratnieks 1993). A recent study showed that the proportion of drones produced by workers during reproductive swarming may reach $6.2 \%$. After the swarming period, the number of worker sons does not exceed 2\% (Holmes et al. 2013). Although this number is much higher than that generally reported, it is still small compared with the queen's reproduction. To make policing effective, workers have to discriminate between queen-laid eggs and worker-laid eggs. One possible source of this information is a 'queen-produced eggmarking pheromone' (Ratnieks and Visscher 1989; Ratnieks 1995; Katzav-Gozansky et al. 1997).

Although the reproduction of workers is rare, there are some cases in which workers lay their own male-determined eggs. Such a situation occurs if a queen dies and the colony has no opportunity to rear a new one (Velthuis 1970; Page and Robinson 1994). Then, 5-24\% of the workers begin laying unfertilized male-determined eggs (Page and Erickson 1988; Miller and Ratnieks 2001). Although worker policing is normally switched off in orphaned colonies (Miller and Ratnieks 2001), but not always (Châline et al. 2004), Ratnieks and Visscher (1989) showed that almost all worker-laid eggs from queenless colonies transferred to queenright tester colonies survived for less than 1 day.

The appearance of workers with mature ovaries in orphaned colonies is not surprising, but the reproduction of workers in queenright colonies is unexpected because the presence of a queen effectively inhibits worker oogenesis (Jay 1970; Velthuis 1970; Page and Robinson 1994; Ronai et al. 2015). However, there are colonies in which workers develop functional ovaries and lay large numbers of eggs that develop into adult drones despite the presence of the queen (Oldroyd and
Osborne 1999). These colonies are called 'anarchistic' (Oldroyd et al. 1994). Oldroyd and Ratnieks (2000) showed that in contrast to the eggs laid by normal workers, anarchist-laid eggs have much greater acceptability in queenright colonies, which suggests that anarchistic workers evade policing, presumably by chemically mimicking eggs laid by the queen. Nevertheless, an anarchistic phenotype is extremely rare and has a genetic component (Barron et al. 2001; Beekman and Oldroyd 2008).

Another type of worker with high reproductive potential - the rebel worker-has recently been discovered (Woyciechowski and Kuszewska 2012). Rebel workers develop immediately after swarming, which is the only natural means of colony multiplication. The proximate factor suggested to affect rebel sub-caste development is the absence of a queen or, more precisely, absence of the queen mandibular pheromone in larval food delivered by the workers (Woyciechowski et al. 2017), whereas the decreased relatedness between the old queen's workers and the new queen's offspring occurring after swarming seems to be the ultimate factor underlying the shift in resource reallocation to reproductive tissue in rebels (Woyciechowski and Kuszewska 2012). Compared with normal workers, rebels exhibit significantly more ovarioles in their ovaries, more developed mandibular and Dufour's glands, and smaller hypopharyngeal glands (Woyciechowski and Kuszewska 2012; Kuszewska and Woyciechowski 2015), which produce brood food (Huang and Otis 1989). These features suggest that the rebel workers are more engaged in laying their own male-determined eggs than in rearing the queen's offspring. A recent study confirmed this suggestion, as Kuszewska et al. (2017) showed that rebels lay their own eggs even in the presence of the queen. Another study showed that 15-day-old rebel workers exhibited active ovaries if they remained in a queenless or a queenright colony during adulthood (Woyciechowski and Kuszewska 2012). However, whether the rebel workers evade worker policing by laying more queen-like eggs remains unknown.

The aim of this study was to determine whether rebel workers, which have high reproductive 
potential reflected in the number of ovarioles in their ovaries and a more advanced state of ovarian development, evade worker policing. For this purpose, we compared the survival of three classes of eggs, namely, those laid by normal workers, rebel workers, and the queen, to test the hypothesis that rebel workers avoid policing by laying more queen-like eggs.

\section{MATERIAL AND METHODS}

\subsection{General experimental procedure}

The experiment was repeated twice. Experiment 1 was conducted from May to July 2016, and experiment 2 was conducted from May to July 2017. Both experiments took place in an experimental apiary at the Institute of Environmental Sciences (Jagiellonian University, Krakow, Southern Poland). In both replicates, queenright honeybee (Apis mellifera carnica) colonies were studied, each consisting of 20,000-40,000 workers. The experiment began with raising rebel and normal workers of similar ages (Fig. 1) to obtain male eggs from the respective groups: normal workers $(\mathrm{N})$, rebel workers $(\mathrm{R})$, and the queen $(\mathrm{Q})$. We used specially designed frames with drone comb divided into six parts (Fig. 2), which could be easily moved from one frame to another similarly constructed test frame to collect eggs from the respective groups. Transferring whole fragments of drone combs, rather than single eggs, prevented the eggs from being destroyed during transfer, as was reported in previous similar experiments (Ratnieks and Visscher 1989; Oldroyd and Ratnieks 2000; Halling et al. 2001). Moreover, this method allowed us to test a larger number of eggs at the same time. The allocation of the fragments of combs with eggs from different groups on the test frame was random. We placed the test frames in queenright, two-story colonies above a queen excluder. Afterwards, we inspected these combs at time intervals to determine which eggs persisted.

\subsection{Experiment 1}

In this experiment, four queenright honeybee (A. m. carnica) colonies were studied. These four colonies were assigned to two pairs with colonies $A$ and $B$ in each pair. Each pair was treated in the same way, but treatment was initiated in the second pair a day after the first pair. The experiment began with raising rebel and normal workers of similar ages (Fig. 1). For this purpose, queens from the A and B colonies were restricted to two experimental frames for $24 \mathrm{~h}$ to produce eggs that would later become normal laying workers (day 0 ), and $48 \mathrm{~h}$ later, both queens were restricted to two other experimental frames to produce eggs that would become rebel workers. Afterwards, the $\mathrm{A}$ and $\mathrm{B}$ colonies were divided into queenright and queenless subunits, with each subunit containing two ( 2 normal or 2 rebel) experimental frames (day 4). The subunits were reunited when the worker cells on the experimental frames were sealed (day 13). Twenty-one days after the experiment began, the frames containing workers reared as larvae under queenright and queenless conditions were placed in an incubator in the laboratory $\left(34{ }^{\circ} \mathrm{C}, 80 \%\right.$ relative humidity). All normal and rebel workers that had recently emerged in an incubator were put into separate hives deprived of the queen and young workers (Fig. 1) to create a situation in which only workers who had emerged in an incubator had a chance to activate their ovaries and start laying eggs. The rebel workers from A and B colonies were combined in a separate hive, and the same was done with normal workers from the experimental frames. This treatment was conducted to increase the number of individuals in the queenless colonies and to avoid the situation in which queenless colonies with rebel or normal workers would not be strong enough to start laying eggs. In this way, we created two queenless colonies: one consisting of rebels and one consisting of normal workers of similar ages. Both groups of workers were related to workers from the queenright colonies A and B, which were used later as discriminator colonies.

After these treatments (day 21), the comb cells were observed for the presence of eggs laid by workers. Once workers in queenless colonies (normal and rebel) began to lay eggs, male eggs were obtained by introducing a modified drone frame (Fig. 2) into each colony. Queens were restricted to this frame for $24 \mathrm{~h}$ using a queen excluder. After $24 \mathrm{~h}$, combs from the frame were 


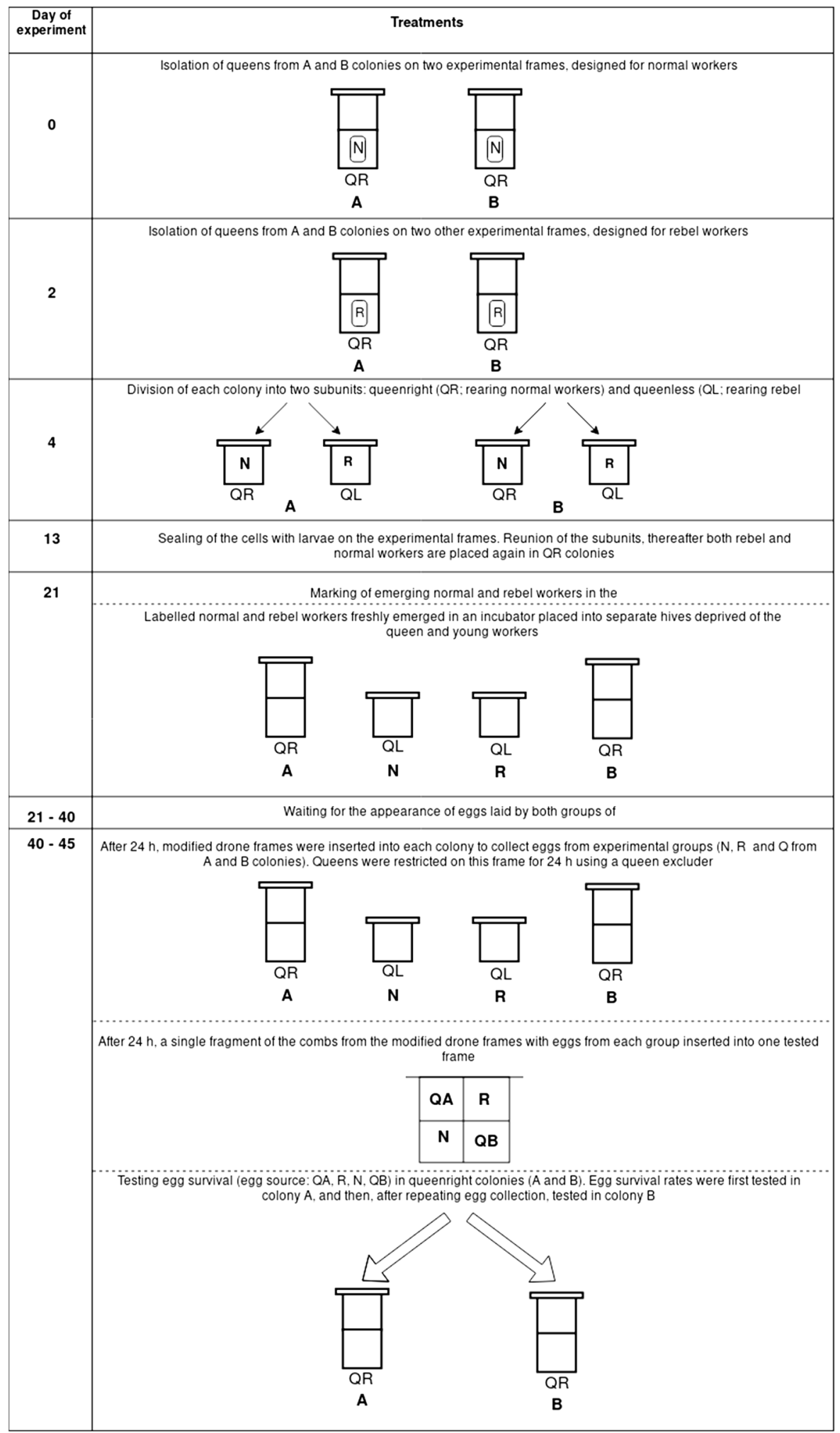

Figure 1. Timeline of experiment 1, showing the manipulations on successive days. 


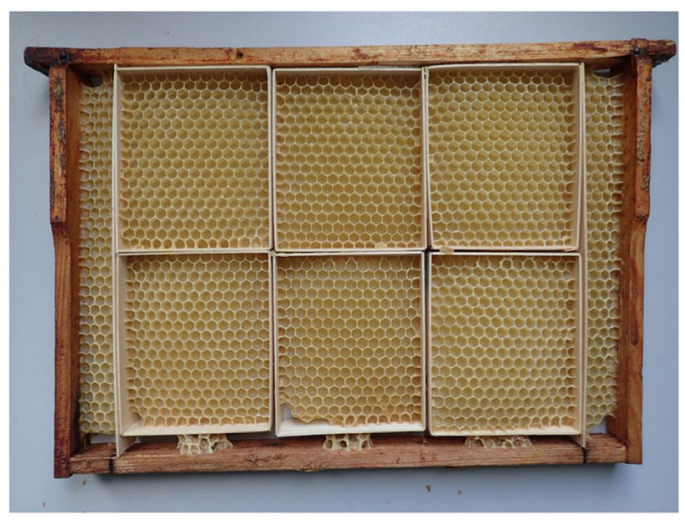

Figure 2. Experimental frame consisting of smaller fragments of drone combs that could be easily exchanged between frames (photo: W. Rojek).

removed, and a single fragment of drone comb with counted eggs from each group was placed in one test frame consisting of four boxes into which we placed comb fragments with tested eggs. All eggs were $24 \mathrm{~h}$ old. In this experiment, we tested the survival of eggs derived from normal $(\mathrm{N})$ and rebel (R) workers and from queens from the A and $\mathrm{B}$ colonies. We tested eggs across pairs, first in colony A and, after repeating the egg collection, into colony B (Fig. 1). This design allowed us to determine any nestmate effects, as discriminator workers compared eggs coming from their own and a foreign queen ( $\mathrm{Q}$ own and $\mathrm{Q}$ foreign, respectively) and from normal and rebel workers (N and $\mathrm{R}$, respectively), which were related to them. The remaining eggs on the test frame were counted every $0.5,1,2,3,4$, and $24 \mathrm{~h}$ (methods of Oldroyd and Ratnieks 2000; Halling et al. 2001; Oldroyd et al. 2001). Counting was performed as quickly as possible, after no longer than $15 \mathrm{~min}$, to reduce the possibility of egg dehydration. We counted cells with eggs independently if one or more eggs were present. The survival of the eggs was tested twice (once in the A colony and once in the B colony) in each pair.

\subsection{Experiment 2}

Discrimination against worker-laid eggs (both rebel and normal) could result from the assessment of the relatedness of the eggs. To exclude this possibility, we performed a second experiment comparing the treatments of eggs laid by the queen, rebel workers, and normal workers in all colonies unrelated to the discriminator. In this experiment, three queenright honeybee (A. m. carnica) colonies were studied. The experimental procedure for each colony was the same as that for experiment 1 , except that unrelated queenright colonies were used as the source of queen eggs and frames with eggs of different origin (N, R, and Q) were tested in unrelated randomly selected queenright discriminator colonies. One queenless colony with normal workers was used twice as a source of $\mathrm{N}$ eggs, as there were no more $\mathrm{N}$ colonies available at the time. To increase the sample size for the N, R, and $\mathrm{Q}$ eggs, two comb fragments from each group were placed in one test frame. To reduce the time required to perform counting, the remaining eggs were recorded by an Olympus TG3 camera. A total of 300 newly emerged normal and rebel workers were marked on the thorax with a spot of paint (Marabu Brilliant Painter) for later assessment of anatomical parameters to confirm that rebel workers significantly differed in their reproductive potential from the normal workers.

\subsection{Examination of anatomical parameters}

Once normal and rebel workers began laying eggs, the labelled individuals were captured and frozen to measure the number of ovarioles. The criterion for a rebel worker is a higher number of ovarioles in the ovary than that in normal workers (Woyciechowski and Kuszewska 2012, Kuszewska and Woyciechowski 2015). The total number of ovarioles in both ovaries of each worker was determined under a stereomicroscope. All ovarioles were stained with Giemsa reagent for approximately $10 \mathrm{~s}$ before being measured.

\subsection{Statistical analysis}

For analysis of the survival data, we used the non-parametric estimator of the lifetime distribution functions proposed by Kaplan and Meier (Kalbfleisch and Prentice 1980). For the analyses, eggs that were present after $24 \mathrm{~h}$ were treated as 
censored data (the failure had not occurred within the observed time). To compare the survival distribution between experimental groups $(\mathrm{N}, \mathrm{R}, \mathrm{Q}$ own, and $\mathrm{Q}$ foreign in experiment 1 , and $\mathrm{N}, \mathrm{R}$, and $\mathrm{Q}$ in experiment 2), we used log-rank tests.

Mixed-model two-way ANOVA was used to compare ovariole number between normal and rebel workers, with the experimental group (reared under queenright or queenless conditions) as a fixed effect and colony as a random effect. If the effect of an experimental treatment was statistically significant, then the ANOVA was followed by multiple comparisons using a post hoc Tukey HSD test, with $p=0.05$ considered significant.

All analyses were performed in Statistica 13.3 (StatSoft, Poland).

\section{RESULTS}

\subsection{Anatomical parameters}

Consistent with the findings of previous studies (Woyciechowski and Kuszewska 2012; Kuszewska and Woyciechowski 2015; Kuszewska et al. 2017), we found that the workers reared under queenless conditions had more ovarioles in their ovaries than the workers reared under queenright conditions (mixed-model two-way ANOVA; $\mathrm{df}=1 ; F=84.74 ; p<0.001)$, confirming that we successfully obtained both normal and rebel workers (Fig. 3a, b).

\subsection{Experiment 1}

The results of tests of the survival of eggs from different experimental groups (N, R, Q own, and $\mathrm{Q}$ foreign ) in the discriminator colonies are presented in Fig. 4, which shows the proportion of eggs surviving $0.5,1,2,3,4$, and $24 \mathrm{~h}$ after the experimental frames with male eggs were placed into the four different discriminator colonies (colonies 1, 2, 3, and 4). A total of $870 \mathrm{~N}, 721 \mathrm{R}, 937$ Q own, and 771 Q foreign eggs were tested. Effective removal of worker-laid male eggs occurred in all colonies (Fig. 4a-d). Eggs laid by both $\mathrm{N}$ and $\mathrm{R}$ were rejected from the tested colonies; a maximum of $20 \% \mathrm{~N}$ and $17 \% \mathrm{R}$ eggs survived for $4 \mathrm{~h}$ (Fig. $4 \mathrm{~d}$ ), and none of the eggs survived to the next day. By contrast, more than $74 \%$ of the Q eggs survived more than $4 \mathrm{~h}$ (Fig. 4a-d). Kaplan-Meier estimates of the survival distributions confirmed that $\mathrm{N}$ and $\mathrm{R}$ eggs were significantly different from Q eggs $(p<0.001$ for both own and foreign queens in all discriminator colonies). In two discriminator colonies, there were no differences in survival between the eggs laid by $\mathrm{N}$ and $\mathrm{R}$ (log-rank test, $p=0.555$ in colony 2 (Fig. 4b); $p=0.095$ in colony 4 (Fig. 4d)), and in two discriminator colonies, eggs laid by $\mathrm{R}$

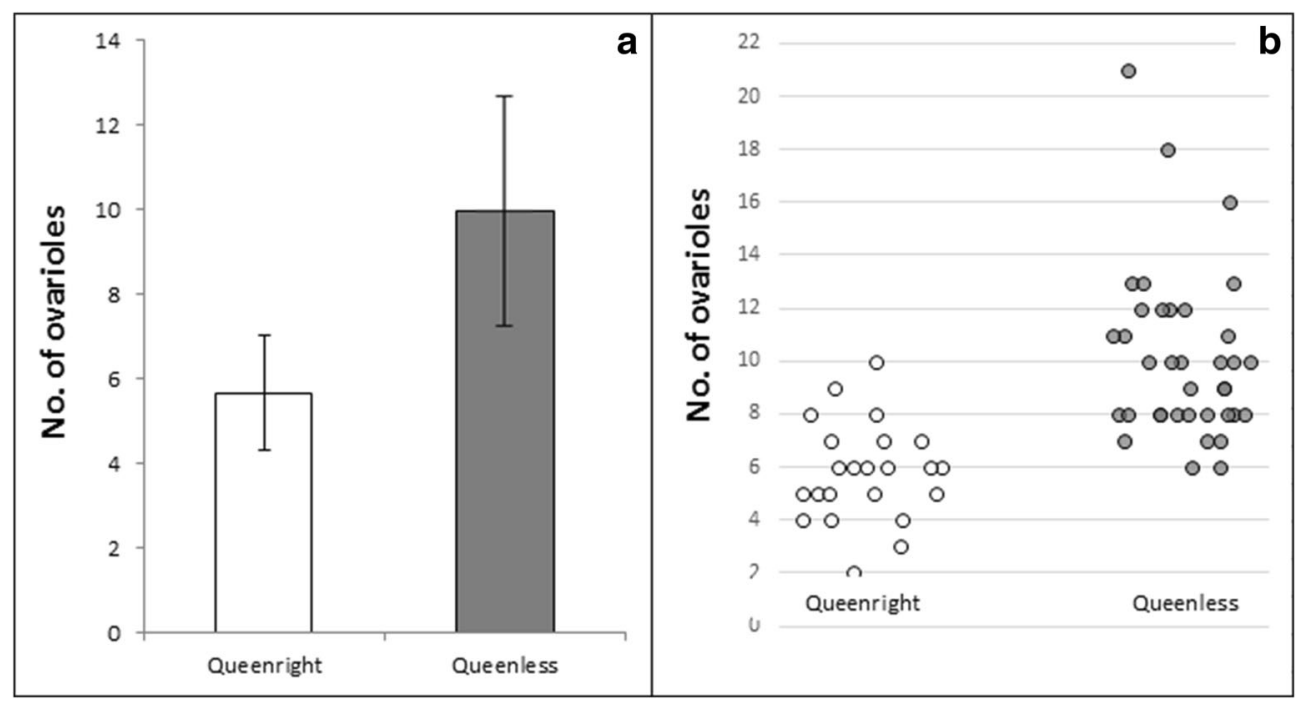

Figure 3. Number of ovarioles of normal and rebel workers. a Mean \pm SD. b Dotplot. 

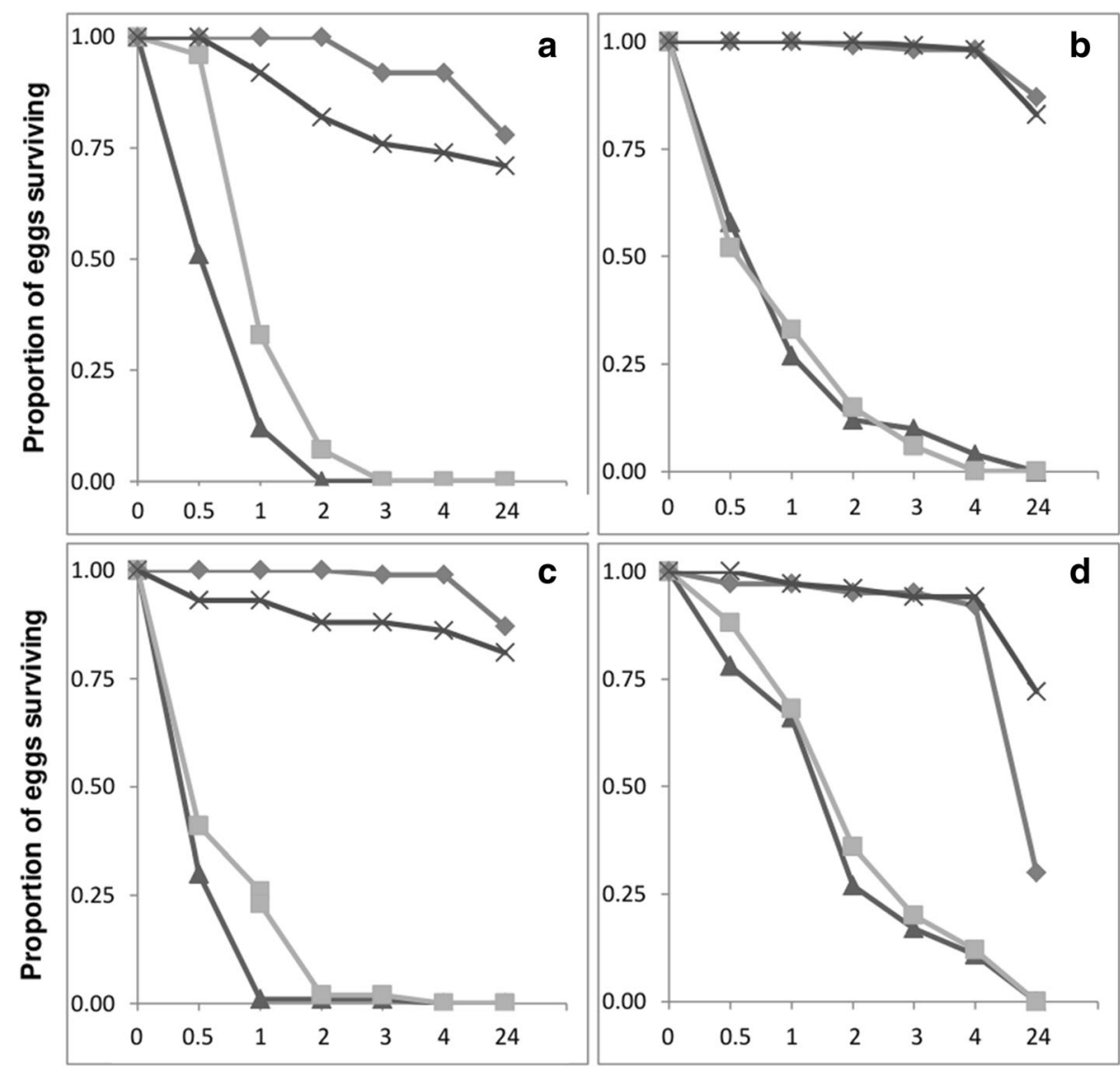

Time (hour)

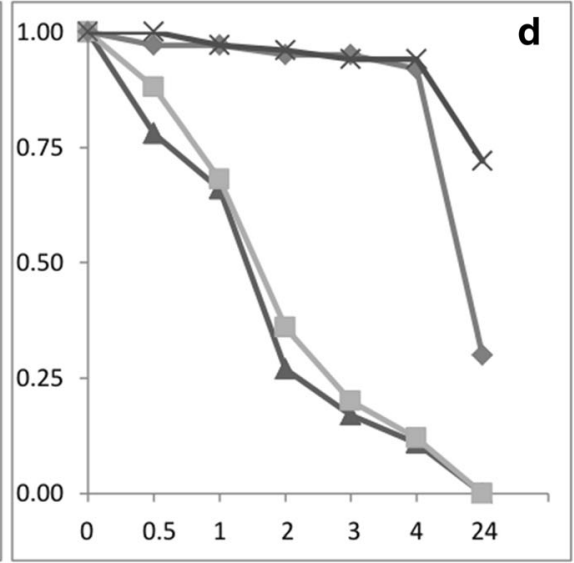

Time (hour)

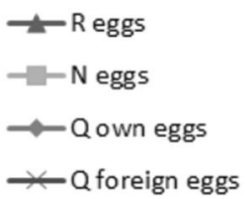

Figure 4. Proportion of eggs surviving from different groups as a function of time in the four discriminator colonies (a-d) obtained from Kaplan-Meier estimates in experiment 1.

were removed significantly faster than those laid by $\mathrm{N}$ (log-rank test, $p<0.001$ in colonies 1 and 3 (Fig. 4a, c). In two discriminator colonies, the eggs laid by Q own had greater acceptance than the eggs laid by Q foreign (log-rank test, $p<0.009$ in colony $1 ; p=0.037$ in colony 3 ). There were no differences in survival between the eggs laid by Q own and those laid by Q foreign in colony 2 (log-rank test, $p=0.297$ ). In colony 4, Q foreign eggs had greater acceptance than the eggs laid by Q own (log-rank test, $p<0.001)$.

\subsection{Experiment 2}

The egg-removal experimental results are presented in Fig. 5. A total of 727 N, 1021 R, and 609 $\mathrm{Q}$ eggs derived from three source colonies were tested in the three unrelated discriminator colonies (colonies 1, 2, and 3). Kaplan-Meier estimates of survival distributions showed that worker-laid eggs were removed by bees significantly more quickly than queen-laid eggs $(p<0.001$ in all discriminator colonies). A maximum of $7 \% \mathrm{~N}$ and $11 \% \mathrm{R}$ eggs survived for $4 \mathrm{~h}$ (Fig. $5 \mathrm{c}$ ), and none of the 

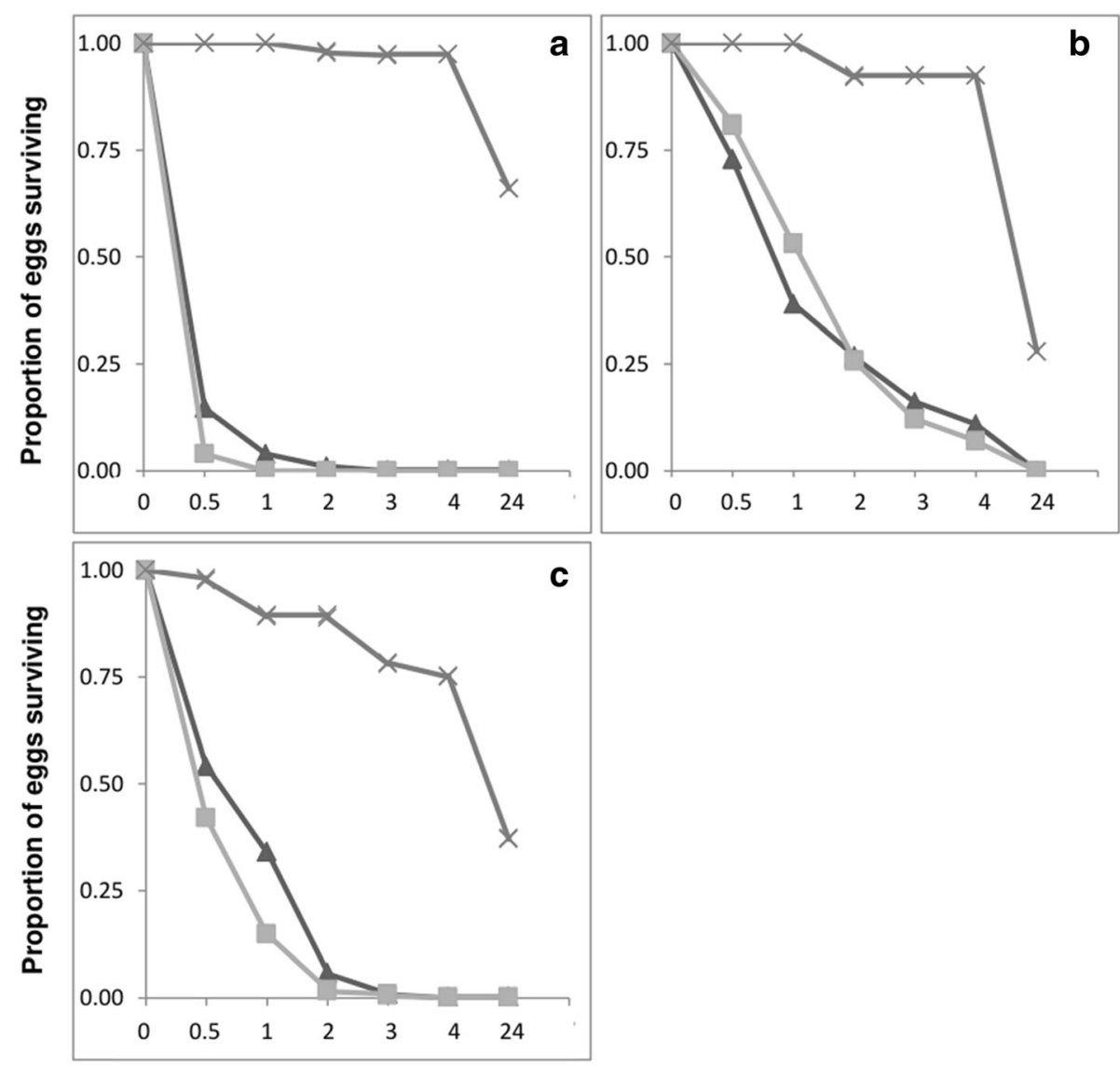

Time (hour)

Time (hour)

$\longrightarrow$ R eggs

$-\mathrm{N}$ eggs

$\multimap Q$ foreign eggs

Figure 5. Proportion of eggs surviving from different groups as a function of time in the three discriminator colonies $(\mathbf{a}-\mathbf{c})$ obtained from Kaplan-Meier estimates in experiment 2.

eggs survived to the next day, whereas $75 \%$ of the $\mathrm{Q}$ eggs survived more than $4 \mathrm{~h}$ (Fig. 5a-c). In two discriminator colonies, eggs laid by $\mathrm{N}$ were removed significantly faster than those laid by $\mathrm{R}$ (log-rank test, $p=0,035$ in colony $1 ;(p<0.001$ in colony 2 (Fig. 5a, b)). In one discriminator colony, there were no differences in survival between the eggs laid by $\mathrm{N}$ and $\mathrm{R}$ (log-rank test, $p=$ 0.565 in colony three (Fig. 5c)), and in two discriminator colonies, eggs laid by $\mathrm{R}$ were removed significantly faster than those laid by $\mathrm{N}$ (log-rank test, $p<0.001$ in colonies 1 and 3 (Fig. 5a, c).

\section{DISCUSSION}

Depending on discriminator colony, the eggs laid by rebel workers were removed at the same rate, faster or slower than the eggs laid by normal workers. Taken together, these results suggest that rebel workers with high reproductive potential in terms of the number of ovarioles in their ovaries (Fig. 3a) do not avoid worker policing. Effective removal of both normal and rebel worker-laid male eggs occurred in all discriminator colonies. Only in two discriminator colonies (colonies 1 and 2, 
experiment 2) did rebel worker-laid eggs have greater acceptability than normal worker-laid eggs; in other colonies, there was either no significant difference or the effect was contrary to the hypothesis. The overall conclusion is that although rebel workers have developed adaptations related to their own reproduction, they have not evolved a special mechanism protecting eggs from policing workers. Unlike the eggs laid by rebel workers, the anarchist-laid eggs have much greater acceptability in queenright colonies than the eggs laid by normal workers, presumably because the anarchists counterfeit the queen-produced egg-marking pheromone (Oldroyd and Ratnieks 2000). Our results are also consistent with the prediction of Holmes et al. (2013) that rebel and normal worker-laid eggs are removed just as often and that the only workers that are able to protect their own offspring are anarchists. Those authors found that after swarming, during which rebel workers usually develop, the number of workers with active ovaries increases, but the number of drones in this period does not change (Holmes et al. 2013). However, recent studies regarding the reproductive potential of workers show that rebel workers have more adult sons than normal workers in queenright colonies (Kuszewska et al. 2017). Consequently, rebel workers not only have a higher reproductive potential than normal workers on the first day of their adult life but also produce male offspring under both queenless and queenright conditions. However, the high reproductive success of rebel workers may result not directly from avoiding worker policing but indirectly from reproductive capacity and the number of eggs laid. Rebels, which have a larger number of ovarioles in their ovaries and a more advanced state of ovarian development (Woyciechowski and Kuszewska 2012), may be capable of laying a larger number of eggs than normal workers, and some of these eggs can survive to adulthood. Makert et al. (2006) show that reproductively successful patrilines of honeybee workers (A. mellifera) not only have a higher ovary status in terms of advanced follicle development but also tend to have more ovarioles per ovary than other workers. Thus, the genetic predisposition of a worker to activate its ovaries after queen loss is associated with the development of the reproductive system during preimaginal stages.
In experiment 1 , we tested if discriminator bees are able to distinguish between eggs from nestmates and non-nestmates. Nestmate recognition would constitute an adaptation to prevent exploitation of the colony by unrelated individuals in light of intraspecific social parasitism. Data from Pirk et al. (2007) revealed a strong effect of nestmate recognition on egg removal in the honeybees A. m. capensis and A. m. scutellata, suggesting that cues other than caste-specific ones can influence egg-removal behaviour. In our experiment in two discriminator colonies, eggs laid by their own queen had greater acceptability than eggs laid by the foreign queen (colonies 1 and 3 ). The opposite pattern occurred in colony 4 , where eggs laid by the foreign queen had greater acceptability, and there was no significant difference between the removal of eggs laid by their own queen and the foreign queen in colony 2 . Based on these results, it is reasonable to conclude that nestmate recognition was not an important factor in the elimination of eggs by discriminator colonies in experiment 1 . This result is consistent with previous findings (Ratnieks and Visscher 1989; Oldroy and Ratnieks 2000) that normal colonies accept queen-laid eggs and reject worker-laid eggs regardless of whether the eggs are from their own colony or a foreign colony. Thus, the effect of nestmate recognition in European honeybees appears to be weaker than the effect of caste. Surprisingly, queen-laid eggs were also removed (after $24 \mathrm{~h}$ in experiment 1,13 up to $70 \%$ of queenlaid eggs were removed, and in experiment 2, 31 up to $72 \%$ were removed) in both experiments, albeit at a lower rate than eggs of normal and rebel workers. The removal of queen-laid eggs has been reported in similar experiments (Ratnieks and Vischer 1989; Oldroyd and Ratnieks 2000; Halling et al. 2001; Châline et al. 2004), even at higher rates: from 54.8\% (Ratnieks and Vischer 1989) to $99.3 \%$ (Châline et al. 2004) of queen-laid eggs were removed after $24 \mathrm{~h}$. One possible explanation for this removal is the cost of worker policing. Kärcher and Ratnieks (2014) showed that $5.7 \%$ of female and $12.5 \%$ of male queenlaid eggs were removed by mistake during discrimination. The other factors affecting queen-laid egg removal in our experiments could be that the amount of brood the colony was prepared to rear 
at that moment had been exceeded or that the eggs were placed in a way that made them difficult to keep warm and later feed. Nevertheless, the results of our experiment are unequivocal: the rebel worker-laid eggs were rejected in queenright colonies as often as the normal worker-laid eggs.

Worker policing evolves in species in which queens are multiply mated, causing workers to be on average more closely related to the sons of their mother than to those of their half-sisters (Woyciechowski and Lomnicki 1987; Ratnieks and Vischer 1989). This phenomenon encourages workers to control the selfish reproductive behaviour of other workers by eating worker-laid eggs. Another possible reason for egg removal is that police workers eat the eggs that are less viable than other male eggs (Velthuis et al. 2002; Pirk et al. 2004; Gadagkar 2004); however, this possibility has been disputed (Beekman and Oldroyd 2005). Different resistance to dehydration among different egg types, which has been found by Wegener et al. (2010), might also have an impact. There is strong evidence that a queen produces egg-marking pheromone and that this pheromone is used by policing workers to distinguish between queen-laid and worker-laid eggs (Ratnieks 1995; Oldroyd et al. 2002). However, the source of chemical labels has yet to be identified (Katzav-Gozansky et al. 2002; Martin et al. 2002; Oldroyd et al. 2002). The shift in resource reallocation to reproductive tissue during development causes rebel workers, more so than normal workers, to be physiologically prepared to lay male-destined eggs and thereby produce sons of their own (Woyciechowski and Kuszewska 2012; Kuszewska et al. 2017). However, the results of our experiment show that the rebel workers do not evade worker policing by laying more acceptable eggs.

Our study shows that rebel worker-laid eggs are removed by policing workers as often as normal worker-laid eggs, which is in contrast to queen-laid eggs, which have great acceptability. Therefore, rebel workers do not possess an adaptation that enables them to protect eggs from policing workers, i.e., by marking eggs with a queen-like secretion. Investing in queen-like egg-marking pheromones is probably a costly strategy, and rebels gain greater reproductive success than normal workers in queenright colonies, most likely through higher egg production.

\section{ACKNOWLEDGEMENTS}

This study was funded by the National Science Centre (NCN) of Poland (grant 2016/23/B/NZ8/ 00803 ) and Jagiellonian University (grant DS/BiNoZ/ INoŚ/761/16-18 and grant 2016/K/DSC/003910). We thank the American Journal Experts for language editing (certificate verification key ACCA-F1CDDAA6-7375-C29P). The funders had no role in the study design, data collection and analysis, decision to publish, or preparation of the manuscript.

\section{AUTHOR CONTRIBUTIONS}

WR, KK, and MW conceived this research and designed the experiments. WR and MOC performed the experiments. WR analysed the data. WR, KK, MW, and MOC wrote the paper and participated in the revisions. All authors read and approved the final manuscript.

\section{COMPLIANCE WITH ETHICAL STANDARDS}

Conflict of interest The authors declare that they have no conflicts of interest.

\section{OPEN ACCESS}

This article is distributed under the terms of the Creative Commons Attribution 4.0 International License (http://creativecommons.org/licenses/by/4.0/), which permits unrestricted use, distribution, and reproduction in any medium, provided you give appropriate credit to the original author(s) and the source, provide a link to the Creative Commons license, and indicate if changes were made.

Les ouvrières rebelles de Apis mellifera évitent-elles le comportement de surveillance?

Comportement de surveillance des ouvrières / ouvrières rebelles / ouvrière pondeuse / Apis mellifera.

Vermeiden rebellische Arbeiterinnen der Honigbiene Apis mellifera Überwachungsverhalten?

Arbeiterinnen Überwachungsverhalten / rebellische Arbeiterinnen / legende Arbeiterinnen. 


\section{REFERENCES}

Barron, A.B., Oldroyd, B.P., Ratnieks, F.L.W. (2001) Worker reproduction in honey-bees (Apis) and the anarchic syndrome: a review. Behav. Ecol. Sociobiol. 50, 199-208

Beekman, M., Oldroyd, B. P., (2005) Honeybee workers use cues other than egg viability for policing. Biol. Lett. 1, 129-132

Beekman, M., Oldroyd, B.P. (2008) When workers disunite: intraspecific parasitism by eusocial bees. Annu. Rev. Entomol. 53, 19-37

Bourke, A.F.G. (1988) Worker reproduction in the higher eusocial Hymenoptera. Q. Rev. Biol. 63, 291-311

Buttel-Reepen, H.V. (1915) Leben und Wesen der Biene, F. Vieweg und Sohn, Braunschweig.

Châline, N., Martin, S.J., Ratnieks, F.L.W. (2004) Worker policing persists in a hopelessly queenless honey bee colony (Apis mellifera). Insectes Soc. 51, 113-116

Dampney, J.R., Barron, A.B., Oldroyd, B.P. (2002) Policing of adult honey bees with activated ovaries is error prone. Insectes Soc. 49, 270-274

Foster, K.R., Wenseleers, T., Ratnieks, F.L.W. (2006) Kin selection is the key to altruism. Trends Ecol. Evol. 21, 57-60

Gadagkar, R., (2004) Why do honey bee workers destroy each other's eggs? J. Biosci. 29(3), 213-217

Halling, L.A., Oldroyd, B.P., Wattanachaiyingcharoen, W., Barron, A.B., Nanork, P., Wongsiri, S. (2001) Worker policing in the bee Apis florea. Behav. Ecol. Sociobiol. 49, 509-513

Hamilton, W.D. (1964a) The genetical evolution of social behaviour I. J. Theor. Biol. 7, 1-16

Hamilton, W.D. (1964b) The genetical evolution of social behaviour II. J. Theor. Biol. 7, 17-52

Holmes, M.J., Oldroyd, B.P., Duncan, M. (2013) Cheaters sometimes prosper: Targeted worker reproduction in honeybee (Apis mellifera) colonies during swarming. Mol. Ecol. 22 , 4298-4306

Huang, Z., Otis, G. (1989) Factors determining hypopharyngeal gland activity of worker honey bees (Apis mellifera L.). Insectes Soc. 36, 264276

Jay, S.C. (1970) The effect of various combinations of immature queen and worker bees on the ovary development of worker honeybees in colonies with and without queens. Can. J. Zool. 48, 169-173

Kalbfleisch, J., Prentice, R. (1980) The statistical analysis of failure time data. John Wiley, New York

Kärcher, M.H., Ratnieks, F.L.W. (2014) Killing and Replacing Queen-Laid Eggs: Low Cost of Worker Policing in the Honeybee. Am. Nat. 184, 110-118

Katzav-Gozansky, T., Soroker, V., Hefetz, A. (1997) Plasticity of caste-specific Dufour's gland secretion in the honey bee (Apis mellifera L.). Naturwissenshaften $\mathbf{8 4}$, 238-241
Katzav-Gozansky, T., Soroker, V., Hefetz, A. (2002) Evolution of worker sterility in honey bees: egg-laying workers express queen-like secretion in Dufour's gland. Behav. Ecol. Sociobiol. 51, 588-589

Kuszewska, K., Woyciechowski, M. (2015) Age at which larvae are orphaned determines their development into typical or rebel workers in the honeybee (Apis mellifera L.). PLoS One 10, e0123404

Kuszewska, K., Wącławska, A., Woyciechowski, M. (2017) Reproduction of rebel workers in honeybee (Apis mellifera) colonies. Apidologie. doi:https://doi. org/10.1007/s13592-017-0537-z

Makert, G.R., Paxton, R.J., Hartfelder, K. (2006) Ovariole number - a predictor of differential reproductive success among worker subfamilies in queenless honeybee (Apis mellifera L.) colonies. Behav. Ecol. Sociobiol. 60, 815-825

Martin, S.J., Jones, G.R., Châline, N., Middleton, H., Ratnieks, F.L.W. (2002) Reassessing the role of the honeybee (Apis mellifera ) Dufours gland in egg marking. Naturwissenschaften 89, 528-532

Miller, D.G., Ratnieks, F.L.W. (2001) The timing of worker reproduction and breakdown of policing behaviour in queenless honey bee (Apis mellifera L.) societies. Insectes Soc. 48, 178-184

Oldroyd, B.P., Osborne, K.E. (1999) The evolution of worker sterility in honey bees: the genetic basis of failure of worker policing. Proc. R. Soc. Lond. 266, 1335-1339

Oldroyd, B.P., Ratnieks, F.L.W. (2000) Evolution of worker sterility in honey-bees (Apis mellifera): how anarchistic workers evade policing by laying eggs that have low removal rates. Behav. Ecol. Sociobiol. 47, 268273

Oldroyd, B.P., Smolenski, A.J., Cornuet, J.M., Crozier, R.H. (1994) Anarchy in the beehive. Nature 371, 749

Oldroyd, B ., Halling, L., Good, G., Wattanachaiyingcharoen, W., Barron, A., Nanork, P., Wongsiri, S., Ratnieks, F. (2001) Worker policing and worker reproduction in Apis cerana. Behav. Ecol. Sociobiol. 50, 371-377

Oldroyd, B.P., Ratnieks, F.L.W., Wossler, T.C. (2002) Eggmarking pheromones in honey-bees Apis mellifera. Behav. Ecol. Sociobiol. 51, 590-591

Page, R.E., Erickson, E.H. (1988) Reproduction by worker honey bees (Apis mellifera L). Behav. Ecol. Sociobiol. 23, 117-126

Page, R.E., Robinson, G.E. (1994) Reproductive competition in queenless honey bee colonies (Apis mellifera L.). Behav. Ecol. Sociobiol. 35, 99-107

Pirk, C.W.W., Neumann, P., Hepburn, R., Moritz, R.F.A., Tautz, J. (2004) Egg viability and worker policing in honey bees. Proc. Natl. Acad. Sci. USA 101, 86498651

Pirk, C.W.W., Neumann, P., Hepburn, R. (2007) Nestmate recognition for eggs in the honeybee (Apis mellifera L.) Behav. Ecol. Sociobiol. 61 , 1685-1693 
Ratnieks, F.L.W. (1988) Reproductive harmony via mutual policing by workers in eusocial Hymenoptera. Am. Nat. 132, 217-236

Ratnieks, F.L.W. (1993) Egg-laying, egg-removal, and ovary development by workers in queenright honey-bee colonies. Behav. Ecol. Sociobiol. 32 , 191-198

Ratnieks, F.L.W. (1995) Evidence for a queen-produced egg-marking pheromone and its use in worker policing in the honey-bee. J. Apic. Res. 34, 31-37

Ratnieks, F.L.W., Visscher, P.K. (1989) Worker policing in the honeybee. Nature 342, 796-797

Ronai, I., Barton, D.A., Oldroyd, B.P., Vergoz, V. (2015) Regulation of oogenesis in honey bee workers via programed cell death. J. Insect. Physiol. 81, 36-41

Van der Blom, J. (1991) Social regulation of egg-laying by queenless honeybee workers (Apis mellifera). Behav. Ecol. Sociobiol. 29, 341-346

Velthuis, H.H.W. (1970) Ovarian development in Apis mellifera worker bees. Entomol. Exp. Appl. 13, 377-394

Velthuis, H. H. W., de Araujo Alves, D., ImperatrizFonseca, V. L., Duchateau M.J., (2002) Worker bees and the fate of their eggs. Proc. Exp. Appl. Entomol. Neth. Entomol. Soc. 13, 97-102

Visscher, P.K. (1989) A quantitative study of worker reproduction in honey bee colonies. Behav. Ecol. Sociobiol. $\mathbf{2 5}, 247-254$

Visscher, P.K. (1996) Reproductive conflict in honeybees: a stalemate of worker egg-laying and policing. Behav. Ecol. Sociobiol. 39, 237-244
Visscher, P. K, Dukas, R. (1995) Honey bees recognize development of nestmates' ovaries. Anim. Behav. $49,542-544$

Wegener, J., Lorenz, M.W., Bienefeld, K. (2010) Differences between queen- and worker-laid male eggs of the honey bee (Apis mellifera). Apidologie. 41, 116-126

Wenseleers, T., Ratnieks, F.L.W. (2006) Comparative Analysis of Worker reproduction and Policing in Eusocial Hymenoptera Supports Relatedness Theory. Am. Nat. 168, 163-179

Wilson, E.O. (1971) The Insect Societies. Belknap Press of Harvard University Press, Cambridge

Woyciechowski, M., Kuszewska, K. (2012) Swarming generates rebel workers in honeybees. Curr. Biol. 22, 707-711

Woyciechowski, M., Lomnicki, A. (1987) Multiple mating of queens and the sterility of workers among eusocial Hymenoptera. J. Theor. Biol. 128, 317-327

Woyciechowski, M., Kuszewska, K., Pitorak, J., Kierat, J. (2017) Honeybee worker larvae perceive queen pheromones in their food. Apidologie. 48(2), 144-149. doi:https://doi.org/10.1007/s13592-016-0459-1

Publisher's note Springer Nature remains neutral with regard to jurisdictional claims in published maps and institutional affiliations. 